\title{
ARTÍCULOS
}

\section{MODERNIDAD Y PROGRESO A TRAVÉS DE LA RECONSTRUCCIÓN MICROHISTÓRICA LITERARIA DEL NORESTE MEXICANO EN NARCEDALIA PIEDROTAS.}

\author{
Anna Marta Marini \\ Instituto Franklin-UAH \\ annamarta.marini@gmail.com
}

Resumen: La centralidad cultural e institucional que ha acompañado el desarrollo de las regiones rurales y periféricas de México ha conllevado un prolongado y generalizado descuido hacia la narración historiográfica de la región norte. La reconstrucción de su dimensión social ha sido retomada por el trabajo de historiadores locales; entre otros Ricardo Elizondo Elizondo (19502013) se destaca por su obra narrativa, en la cual se expresa su trabajo historiográfico a través de una ficción cercana al relato microhistórico. El presente artículo propone, por lo tanto, una aproximación a la microhistoria del noreste entre el fin de las luchas revolucionarias y el surgimiento de las políticas neoliberales, siguiendo la línea expertamente marcada por la novela coral de Elizondo Narcedalia piedrotas (1993) y reconstruyendo de ahí la relación entre contexto histórico y narración literaria.

Palabras clave: Frontera, Ricardo Elizondo Elizondo, literatura mexicana, microhistoria, desarrollo tecnológico, Norte mexicano.

Tittle: MODERNITY AND DEVELOPMENT THROUGH THE LITERARY RECONSTRUCTION OF A MICROHISTORY OF THE MEXICAN NORTHEAST IN NARCEDALIA PIEDROTAS.

Abstract: Cultural and institutional centralism has characterized the development of rural and liminal regions of Mexico, entailing a prolonged and generalized neglect towards historiographic narration of the Northern region. The reconstruction of its social dimension has been picked up through the work of local historians; among a few, Ricardo Elizondo Elizondo (1950-2013) stands out thanks to his literary work, in which his historiographic research is conveyed through microhistory-related fiction. Thus, this research paper suggests an approximation to the Mexican Northwest microhistory between the end of the revolutionary conflicts and the rise of neoliberal politics, following the trace marked by Elizondo's coral novel Narcedalia piedrotas (1993) and reconstructing the relation existing between historical context and literary narrative.

Keywords: Borderlands, Ricardo Elizondo Elizondo, Mexican literature, microhistory, technological development, US-Mexico border.

Cómo citar este artículo: MARINI, Anna Marta. Modernidad y progreso a través de la reconstrucción microhistórica literaria del noreste mexicano en Narcedalia piedrotas. Naveg@mérica. Revista electrónica editada por la Asociación Española de Americanistas [en línea]. 2020, n. 24. Disponible en: <http://revistas.um.es/navegamerica>. [Consulta: Fecha de consulta]. ISSN 1989-211X. 


\section{Introducción}

A principios del siglo XXI, se puede observar un paulatino descubrimiento de la dimensión histórica regional norteña de México ${ }^{1}$, más allá de su relevancia desde un punto de vista económico y político en las relaciones binacionales. El prolongado descuido hacia la narración historiográfica de la región norte deriva de la enraizada centralidad cultural e institucional que ha acompañado el desfase existente en el desarrollo de las regiones rurales y periféricas de México. Sin embargo, en el último cuarto del siglo XX se han destacado algunas obras literarias que intentan reconstruir la realidad cotidiana de la región basándose en un esmerado trabajo historiográfico de alcance local; en ese sentido, entre otros, el historiador y escritor Ricardo Elizondo Elizondo (1950-2013) representa un caso paradigmático. A lo largo de su carrera de académico e historiador de a pie, se preocupó de reconstruir la historia privada del noreste y estudiar rasgos lingüísticos, convenciones y estructuras sociales; asimismo trabajó con archivos fotográficos, institucionales y de empresas locales. En sus novelas históricas, Elizondo recrea por ende el contexto norestino a través de una narración de carácter microhistórico, en la cual los hechos macrohistóricos sirven de fondo para una perspectiva de lectura enfocada en la cotidianidad. A pesar de su condición de marcada liminalidad con respecto al centro del país, su proximidad con Estados Unidos y su naturaleza profundamente fronteriza han permitido a la región norteña vivir los avances técnicos y gozar de los productos del progreso cotidianamente. Precisamente el desarrollo tecnológico y su papel en la vida de la población representan un tema recurrente en la narrativa de Elizondo; de la evolución de los medios de transporte hasta la difusión de técnicas agrícolas e industriales- innovadoras, su reconstrucción proporciona indicios para entender el actual desarrollo del estado norestino de Nuevo León. En su obra la narración literaria se funde con el quehacer historiográfico para reproducir y delinear una realidad a menudo omitida, hacia una construcción tanto histórica como identitaria de la región. En particular, su novela coral Narcedalia Piedrotas (1993) se desarrolla en el marco cronológico que va desde el fin de las luchas revolucionarias hasta el surgimiento de las políticas neoliberales a principio de los años 80 . La reconstrucción contextual y narrativa proporcionada por esta novela permite apreciar una meticulosa reconstrucción microhistórica, derivada del extenso trabajo historiográfico al cual Ricardo Elizondo Elizondo dedicó su vida.

\section{La reconstrucción historiográfica de la región norte mexicana}

La región que se considera como noreste mexicano abarca los estados de Coahuila, Nuevo León y Tamaulipas. La demarcación territorial política corresponde de manera aproximada a una región que comparte rasgos culturales y etnolingüísticos, pues el noreste históricamente comprende zonas de Texas y no incluye algunas zonas que actualmente forman parte de los estados federales mencionados ${ }^{2}$. La región reconocida como noreste en sentido histórico elude, por lo tanto, la partición administrativa; una identidad común asimila poblaciones de ambos

\footnotetext{
${ }^{1}$ ORTEGA RIDAURA, Isabel. Introducción. En: ORTEGA RIDAURA, Isabel. El noreste: reflexiones. Monterrey: Fondo Editorial de Nuevo León, 2006, p. 11.

2 ELIZONDO ELIZONDO, Ricardo. Un lexicón del noreste. En: ORTEGA RIDAURA, Isabel. EI noreste: reflexiones. Monterrey: Fondo Editorial de Nuevo León, 2006, p. 196.
} 
lados de la frontera, en relaciones que -desde tiempos prefronterizos- no dependen de cuestiones jurídicas o políticas ${ }^{3}$. En tiempos prehispánicos el norte mexicano se encontraba diseminado por poblaciones indígenas a menudo nómadas, sin estructuras sociales o urbanas articuladas como acontecía en el centro y sur del país ${ }^{4}$. Durante la colonia española el norte permaneció como una región relativamente difícil de gestionar; las condiciones climáticas y orográficas resultaban hostiles, además de las dificultades representadas por las tribus locales. Los asentamientos coloniales eran atacados y despojados frecuentemente, abandonados y refundados varias veces. La colonización del área dependía, por lo tanto, de una red de presidios, constituidos por un fuerte, una misión y unos cuantos edificios necesarios para el desarrollo de las actividades cotidianas de la comunidad. La definición del espacio ya estaba establecida por las poblaciones antecedentes, conque los colonizadores se limitaron a apropiarse y ocupar regiones relativamente poco pobladas, realmente sin imponer reparticiones ni tener los inmensos territorios norteños bajo un control administrativo efectivo. La colonia y luego el gobierno mexicano tuvieron conflictos constantes con las poblaciones indígenas locales; la destrucción -eficaz, aunque no organizada de manera sistemática- de tales poblaciones indígenas afectó en particular las pertenecientes al grupo etnolingüístico apache.

Cuando se formó el estado mexicano a raíz de los procesos de independencia, las principales actividades a lo largo de la franja fronteriza mexicana eran la ganadería y la agricultura, cuyos productos a menudo se vendían localmente. Como se destacará más adelante a través del análisis del aporte microhistórico intrínseco a la novela Narcedalia Piedrotas, la prosperidad de las comunidades fronterizas dependía de la especialización en distintos sectores de la ganadería, sobre todo en el ámbito bovino y acemilar. La organización administrativa local quedaba afectada por la distancia del gobierno central y un sentimiento independentista permanecía en la región. Establecido por decreto en 1835, el centralismo gubernamental alimentó el conflicto sociopolítico hasta su forzada supresión en $1848^{5}$. Durante su vigencia, movimientos secesionistas se articularon en ambos lados del Río Grande, asimilando los intentos de federalismo e independencia de Texas y de la región norestina. El movimiento federalista de las villas del norte se compuso de fenómenos variados, que buscaban la garantía de cierta independencia a través del federalismo y que habían sido estimulados por el éxito texano de 1836. En 1839 el gobierno de Texas decidió quitar su apoyo a los federalistas mexicanos, aun preservando el intercambio comercial fronterizo ${ }^{6}$; en marzo de 1840 fue proclamada la República del Río Grande, compuesta por los estados norestinos de Coahuila, Nuevo León, Tamaulipas, y algunas regiones limítrofes. Unos meses más tarde los secesionistas tuvieron que rendirse y pactaron con el gobierno mexicano ${ }^{7}$. A pesar de la relevancia

\footnotetext{
${ }^{3}$ CEBALLOS RAMÍREZ, Manuel. La conformación del noreste histórico mexicano: larga duración, identidad y geopolítica. Secuencia. 2006, n. 65, p. 10.

${ }^{4}$ CARR, Barry. Las peculiaridades del norte mexicano, 1880-1917. Historia Mexicana. 1973, vol. 22, n. 3, p. 322.

${ }^{5}$ VÁZQUEZ, Josefina Zoraida. La supuesta República del Río Grande. Historia Mexicana. 1986, vol. 36 , n. 1 , p. 51.

${ }^{6}$ Ibídem, p. 55.

${ }^{7}$ GREEN, Stanley. C. La república del Río Grande y Nuevo León. En: ORTEGA RIDAURA, Isabel. El noreste: reflexiones. Monterrey: Fondo Editorial de Nuevo León, 2006, p. 55.
} 
del conflicto, especialmente en perspectiva fronteriza y de definición de los límites estatales, los periódicos nacionales dedicaron escasa atención al asunto; por el contrario, los periódicos texanos y del sur de Estados Unidos cubrieron ampliamente los enfrentamientos, describiendo detalladamente las luchas de los federalistas de las villas norteñas ${ }^{8}$. Si bien la obra literaria de Ricardo Elizondo Elizondo no se enfoca directamente en la cuestión independentista, a lo largo de Narcedalia Piedrotas resulta evidente la permanencia de una actitud recelosa y hasta hostil de los pobladores fronterizos hacia el gobierno central y su posible -aunque casi inexistente en la práctica- injerencia. La distancia se percibe claramente a lo largo de la novela, pues el pueblo ficticio en el cual se desarrollan los hechos está "tan lejos de la capital, abandonado por siglos a su propia voluntad y justicia"'.

La política expansionista de Estados Unidos llevó a una serie de conflictos conocidos como la Guerra México-Americana (1846-1848), que terminó con la firma del Tratado de Guadalupe Hidalgo y el consecuente trazado de un confín político entre México y Estados Unidos, establecido definitivamente en 1854. Desde ese momento, la región fronteriza transnacional dividida por el Río Grande se volvió eje de la economía fronteriza. El régimen conocido como Porfiriato (1876-1911) -durante el cual gobernó casi ininterrumpidamente el general Porfirio Díaz- representó un periodo de relativa paz y desarrollo económico para el país, que gozó de consistente inversión extranjera y concentró el poder en manos de una oligarquía que acabó con cacicazgos locales ${ }^{10}$. Uno de los logros fundamentales del Porfiriato fue la construcción y operación de una red ferroviaria que conectaba los centros urbanos del país, llegando hasta los cruces fronterizos principales. En la región norteña, una nueva prosperidad fue impulsada por el planteamiento de actividades mineras, que llegaron a representar la mayor riqueza del norte junto con la ganadería y la agricultura intensivas; a menudo, las empresas que explotaban estos sectores eran de propiedad estadounidense, lo que vinculó aún más estrechamente la economía del norte de México y del sur de Estados Unidos ${ }^{11}$.

Durante la Revolución -desatada con ocasión de las elecciones presidenciales en 1910 y fomentada por una radicada oposición al régimen porfirista- los estados norteños tuvieron notable importancia estratégica, en particular en el noroeste y en el territorio del estado de Sonora. En la frontera, y sobre todo a lo largo del Río Grande, se articularon además varias comunidades de exiliados revolucionarios ${ }^{12}$ y poblaciones de civiles que, simplemente, intentaban huir de la guerra civil y sus desastrosas consecuencias. Después de las luchas revolucionarias, la infraestructura de la red ferroviaria necesitó de obras de reconstrucción relevantes; con su expropiación en 1937 por parte del gobierno cardenista, los Ferrocarriles Nacionales de México fueron incorporando las demás empresas existentes en el territorio, volviendo el sistema ferroviario un eje estratégico para la economía

\footnotetext{
${ }^{8}$ VÁZQUEZ, Josefina Zoraida. La supuesta República... Op. cit., p. 58 y ss.

${ }^{9}$ ELIZONDO ELIZONDO, Ricardo. Narcedalia Piedrotas. $2^{\underline{a}}$ ed. Ciudad de México: Fondo de Cultura Económica, 2002, p. 74. Con relación a la edición señalada, de aquí en adelante, se pondrán entre paréntesis, tras su cita correspondiente, las páginas referenciadas del texto de la novela aquí tratada.

${ }^{10}$ SÁNCHEZ ANDRÉS, Agustín. México en el siglo XX: del Porfiriato a la globalización. Madrid: Arco Libros, 2010, p. 8.

${ }_{11}$ CARR, Barry. Las peculiaridades... Op. cit., p. 325.

${ }^{12}$ CARR, Barry. Las peculiaridades... Op. cit., p. 331.
} 
nacional $^{13}$. La retórica institucional que caracterizó los gobiernos inmediatamente posrevolucionarios propugnaba la unidad nacional. El discurso nacionalista mexicano posrevolucionario se fundó en la creación de una identidad nacional basada en personajes históricos mitificados, la teorización de una supuesta raza mestiza mexicana y la invención de una unidad cultural que en realidad no existía como tal. La iconografía y los motivos nacionales retomaron varios rasgos de las culturas, las costumbres y el folclore locales, creando una mezcla bastante selectiva y no representativa de muchas de las poblaciones existentes a lo largo del territorio mexicano. Además de ver su cultura no reconocida en la esfera pública nacional, muchos grupos indígenas resultaron excluidos de los mapas antropológicos trazados por el Instituto Nacional de Antropología e Historia (INAH, fundado en 1939 durante el mandato de Lázaro Cárdenas), institución que tuvo un papel fundamental en el desarrollo y articulación de una política cultural de estado ${ }^{14}$. La frontera quedó como un lugar liminal y caracterizado por su distancia -cultural además de espacial- del estado federal, así como por su sospechosa cercanía con el país vecino; el desarrollo del ambiente cultural nacional se asentaba en la capital, dejando la región norte a menudo olvidada.

Desde un punto de vista económico, la consolidación del estado y sus instituciones federales y estatales permitió la construcción de un espacio de intercambio binacional, que ha ido desarrollándose y fortaleciéndose a lo largo del siglo $X X^{15}$. Con respecto al desarrollo industrial y comercial de la región, se puede reconstruir muy parcialmente su impacto social a través de los trabajos historiográficos que se focalizan en las empresas mexicanas, impulsados con la creación de la Asociación de Historia Económica del Norte de México (AHENME) en 1992. La convergencia entre historia económica y estudios empresariales por la asociación ha contribuido a un incremento notable en la producción académica sobre las empresas regionales a lo largo de la historia nacional, como bien pudo destacar Cerutti en su informe de 2017 sobre el tema ${ }^{16}$.

Los estudios recientes sobre el crimen organizado y sus dinámicas también han permitido un acercamiento a la historia contemporánea de la región, aun desde una perspectiva muy específica. Por evidentes razones geohistóricas, los problemas relacionados con el narcotráfico han ido difundiéndose e intensificándose en la región norte, cuyas ciudades fronterizas se han vuelto escenario de un conflicto constante y violento. De la misma manera, los estudios que encaran la cuestión de la migración fronteriza hacia Estados Unidos permiten entender -aun parcialmentela complejidad de las dinámicas laborales en las borderlands. Si bien entre el último cuarto del siglo XIX y el fin de las luchas revolucionarias los empresarios estadounidenses contrataban trabajadores mexicanos de manera ilegal por medio de mecanismos de indenture, a lo largo del siglo $\mathrm{XX}$ se fueron implementando

\footnotetext{
${ }^{13}$ MÁRQUEZ MARTíNEZ, Teresa. Los archivos de ferrocarriles nacionales de México. América latina en la historia económica. 2005, n. 23, p. 121.

${ }^{14}$ YÁÑNEZ REYES, Sergio. El Instituto Nacional de Antropología e Historia: antecedentes, trayectoria y cambios a partir de la creación del CONACULTA. Cuicuilco. 2006, vol. 13, n. 38, p. 57.

${ }^{15}$ CERUTTI, Mario. Frontera y desarrollo empresarial en el norte de México (1850-1910). Frontera Norte. 2001, vol. 13, n. 2, p. 284.

${ }^{16}$ CERUTTI, Mario. La historia económica y empresarial del norte de México: un cuarto de siglo de investigación. Monterrey: Universidad Autónoma de Nuevo León; AHENME, 2017.
} 
políticas binacionales para promover el trabajo estacional de migrantes mexicanos ${ }^{17}$. Los acuerdos y programas dependían fundamentalmente de un mecanismo de demanda y oferta focalizado en el mercado estadounidense, favoreciendo, por lo tanto, la estructuración de relaciones de poder desiguales entre los dos países y la consolidación de la explotación estadounidense de la mano de obra mexicana. Evidentemente, las poblaciones fronterizas se han encontrado en una posición física y socialmente apta al desarrollo de relaciones laborales vinculadas con el otro lado, desde migraciones temporales hasta trabajo transfronterizo.

Sin embargo, la historiografía social y privada regional norteña sigue siendo alimentada sobre todo por historiadores y autores locales, que desarrollan su trabajo a través de archivos institucionales regionales, pero también archivos privados, familiares y de pequeñas fundaciones. La obra historiográfica de Ricardo Elizondo Elizondo se revela interesante en este sentido; si bien, por ejemplo, la Secretaría de Cultura (a través de los archivos literarios del Instituto Nacional de Bellas Artes) solo lista sus pocas obras de alcance nacional, el investigador fue muy prolífico con respecto a publicaciones relacionadas con la historia norestina. Su extenso trabajo en archivos emerge en toda su obra; Elizondo fue nombrado director del Archivo General del Estado de Nuevo León (1975-1979) y después asumió el encargo de director de la Biblioteca Cervantina y Patrimonio Cultural del Instituto Tecnológico y de Estudios Superiores de Monterrey (ITESM), institución en la que trabajó toda su vida académica. Asimismo, trabajó con fondos documentales locales no institucionales, enfocando su trabajo en particular en el examen de colecciones fotográficas privadas y de correspondencia de migrantes y pobladores de la región fronteriza; escribió ensayos -a menudo publicados por el ITESM mismo- sobre la sociedad norestina y su estrecha relación con el territorio, siendo la historia privada su mayor interés. En su versátil actitud hacia la historia en general y su divulgación, se ocupó de adaptaciones multimedia de textos historiográficos y de redacción de textos escolares.

La inquietud historiográfica de Elizondo está evidentemente vinculada al contexto norestino y a su producción de localidad, es decir, a esa esencia propia de un lugar histórica y socialmente construido ${ }^{18}$. Su habilidad descriptiva de la realidad norteña, fronteriza y rural reside precisamente en su esmerada investigación y repetido contacto directo -casi de carácter antropológico de campo- con el territorio norestino y sus pobladores. Su dedicación aflora de manera sutil a través de sus eficaces narraciones, descripciones esenciales y acertadas, miradas discretas sobre la vida doméstica de los pobladores norteños.

\section{Narcedalia Piedrotas y la microhistoria norestina}

Paralelamente a su extenso trabajo historiográfico, Ricardo Elizondo Elizondo publicó dos novelas históricas que tuvieron bastante éxito de crítica. Se trata de Setenta veces siete (1987) y Narcedalia Piedrotas (1993), escritas y publicadas

\footnotetext{
${ }^{17}$ DURAND, Jorge. Historia mínima de la migración México-Estados Unidos. Ciudad de México: EI Colegio de México, 2016.

${ }^{18}$ DE VITO, Christian G. Verso una microstoria translocale (micro-spatial history). Quaderni storici. 2015, n. 3, p. 817.
} 
después de una serie de relatos breves; la colección Relatos de mar, desierto y muerte (1981) fue su debut editorial en el campo literario, publicado después de haber ganado el primer premio en el Concurso de Cuento del Gobierno de Zacatecas en 1980. Ganadora del Premio Colima para obras publicadas en 1988, Setenta veces siete sigue siendo su obra narrativa más conocida, con la cual más se identifica su pertenencia al grupo fundador surgido a finales de los años 70 de la llamada "narrativa del desierto", junto a autores como Gerardo Cornejo, Severino Salazar, Miguel Méndez, Jesús Gardea y Daniel Sada. Como ha destacado Vicente Francisco Torres ${ }^{19}$ a lo largo de su obra académica y de crítica literaria, se trata de un grupo de escritores cuyo papel fue axial en la regeneración de la literatura mexicana en esos años. Al igual que Cornejo, Elizondo trata el desierto como contexto fundamental para la identidad norteña, tomándolo como un espacio material y textual a la vez, en el cual se trazan evoluciones y acontecimientos históricos. Se trata de una narrativa para la cual el territorio y la identidad geohistórica resultan centrales en el sistema sociocultural de las poblaciones locales; por lo tanto, su relación con el medio que las circunda influencia profundamente la producción artística, literaria y poética de la región. La articulación del paisaje a lo largo de las narrativas norteñas parece casi una extensión de los personajes y del escritor mismo ${ }^{20}$. El profundo interés demostrado por Elizondo hacia las fuentes fotográficas y los archivos de correspondencias particulares surge de su obra narrativa, en la cual propone descripciones a menudo caracterizadas por una estética evocativa de la fotografía ${ }^{21}$. Su extenso trabajo de investigación a lo largo del territorio norestino, llevada a cabo personalmente recorriendo caminos, entrevistando habitantes de la región y explorando sus archivos familiares, se revela a través de una narración literaria que recuerda el cuento y la historia oral.

En la literatura norteña, el papel de la frontera -como confín material y zona sociocultural transnacional- es fundamental; el mismo Elizondo expresa la naturaleza porosa e híbrida de la región binacional, destacando que la línea fronteriza "aunque clarísima en los mapas, era perfectamente invisible en la realidad" ${ }^{22}$. Al enfrentarse a la reconstrucción de la microhistoria social fronteriza hay que considerar el carácter cotidiano del intercambio sociocultural en la región binacional, que resulta normalizado y necesario aunque evidentemente dispar ${ }^{23}$. Es más, la transnacionalización cultural ${ }^{24}$ implica necesariamente una constante negociación y redefinición de la identidad y de lo nacional; la existencia en la frontera conlleva el desarrollo de un así llamado cross-border state of mind $^{25}$ influenciado por

19 TORRES, Vicente Francisco. Esta narrativa mexicana. Ed. revisada. Ciudad de México: Universidad Autónoma Metropolitana, 2007; y TORRES, Vicente Francisco. Un maestro del desierto y del estilo. Tema y variaciones de literatura. 2012, semestre I, n. 38, pp. 141-159.

${ }^{20}$ GÚZMAN, Nora. Todos los caminos conducen al norte: la narrativa de Ricardo Elizondo Elizondo y Eduardo Antonio Parra. Monterrey: Fondo Editorial de Nuevo León, 2009, p. 36.

${ }_{21}$ MARINI, Anna Marta. Narcedalia Piedrotas y la construcción microhistórica de la identidad fronteriza norteña. n América sin Nombre. 2018, n. 23, p. 204.

${ }_{22}$ ELIZONDO ELIZONDO, Ricardo. Setenta veces siete. Ciudad de México: Leega, 1987, p. 21.

${ }^{23}$ PARDO FERNÁNDEZ, Rodrigo. La ficción narrativa de la frontera: el río Bravo en tres novelas mexicanas. Frontera Norte. 2013, vol. 25, n. 49, p. 165.

${ }^{24}$ GARCÍA CANCLINI, Néstor. Culturas híbridas. Estrategias para entrar y salir de la modernidad. Ciudad de México: Grijalbo, 1990, p. 25.

${ }_{25}$ DEAR, Michael y LECLERC, Gustavo (eds.). Postborder city. Cultural spaces of Bajalta California. Nueva York: Routledge Publishing, 2003. 
el contacto inevitable con el respectivo otro lado y su intrínseca otredad. Desde el trazo de la frontera política, la identidad de los habitantes de la región ha sido caracterizada por la hibridez cultural y etnolingüística; además de los escritores norteños en su obra literaria, los estudiosos locales han evidenciado el desarrollo de una identidad híbrida en los estados del norte de México ${ }^{26}$. La relación con el vecino estadounidense permanece evidentemente ambivalente: si bien la común liminalidad acerca los norteños al sur de Estados Unidos por costumbres, valores, cultura y experiencia social, al mismo tiempo, hay una reivindicación de la cultura norteña mexicana como tal, distinta de la estadounidense. La frontera entre México y Estados Unidos se caracteriza por discursos e imágenes contradictorios ${ }^{27}$, pues en realidad la enraizada hibridación sociocultural y etnolingüística de sus poblaciones choca con el significado esencial de la frontera misma como división, fuente de diferencias igualmente profundas. En ese sentido, en el espacio sociocultural transnacional se materializan las relaciones de poder desequilibradas entre los dos países vecinos y los conflictos socioeconómicos -internos y externos- existentes.

Además, hay que destacar que -tanto en Narcedalia Piedrotas como en Setenta veces siete- Elizondo emplea de manera coherente elementos lexicales propios del noreste mexicano gracias a su propio trabajo de recolección sociolingüística; su estudio Lexicón del Noreste de México (1996) es el único trabajo orgánico existente sobre el habla propia del noreste y su léxico peculiar. Su contribución integra el estudio sintáctico y lexicográfico de los dialectos regionales llevado a cabo por Francisco J. Santamaría en su Diccionario de mejicanismos $(1959)^{28} \mathrm{y}$, consecuentemente, por el Colegio de México por medio del desarrollo de un Diccionario básico del español de México (publicado por primera vez en 1991). Su esmerado trabajo lexicográfico aflora sobre todo en Narcedalia Piedrotas, novela en la que se encuentran repetidamente términos descritos exclusivamente por su diccionario, a pesar de ser empleados corrientemente en el habla norteña y en particular norestina ${ }^{29}$.

Elizondo ambienta Narcedalia Piedrotas ${ }^{30}$ en el pueblo ficticio de Villa Perdomo, cerca de la frontera estadounidense y en la región norestina; poco más al norte "de donde está Perdomo termina el país. Un río grande -tan grande que así se llamaes el límite" (p. 83). La novela es coral, compuesta de distintos hilos narrativos que se desarrollan alrededor de la familia Vega, revelando un interés de Elizondo por la reconstrucción genealógica de la historia particular ${ }^{31}$. Narcedalia Vega -apodada Piedrotas por un hecho de juventud-por varias vicisitudes se encuentra al mando de su familia, sola después de la muerte del padre y de la decisión de su hermana Guadalupe de hacerse monja quedándose en el convento donde la educaron. Fea y

\footnotetext{
${ }^{26}$ GÚZMAN, Nora. Todos los caminos... Op. cit., p. 39.

${ }_{27}$ GRIMSON, Alejandro. Las culturas son más híbridas que las identificaciones: diálogos interantropológicos. Anuário Antropológico. 2008, vol. 33, n. 1, pp. 223-267.

${ }_{28}$ SANTAMARÍA, Francisco J. Diccionario de mejicanismos. Ciudad de México: Editorial Porrúa, 1959.

${ }^{29}$ MARINI, Anna Marta. Narcedalia Piedrotas... Op. cit., p. 204.

${ }^{30}$ Se hace referencia a esta edición: ELIZONDO ELIZONDO, Ricardo. Narcedalia Piedrotas.Op. cit.

${ }^{31}$ RODRÍGUEZ LOZANO, Miguel G. Notas en torno al mundo narrativo de Ricardo Elizondo Elizondo. Proyecto Hacia una microhistoria literaria: Gerardo Cornejo, Jesus Gardea, Ricardo Elizondo y Daniel Sada. Ciudad de México: Universidad Nacional Autónoma de México, 1998, p. 515.
} 
de carácter huraño, Narcedalia se revela una empresaria capaz y sagaz, particularmente hábil en los negocios fronterizos. Aun cuando se casa con Valentín y tiene un hijo, su vida sigue enteramente dedicada al desarrollo de sus actividades lucrativas, desde la cría de marranos hasta el único cine del pueblo. Sin embargo, la llegada de Valentín -joven atractivo y bastante tonto- a Perdomo implica más adelante la llegada del narcotráfico y sus negocios; excluido de las actividades familiares y decidido a emprender sus propios negocios, el marido de Narcedalia se involucra con el crimen organizado de manera torpe e ingenua, perjudicando finalmente la suerte de toda la familia. Las líneas narrativas, que se entrelazan con la línea principal, se enfocan en el pueblo mismo; además de las vicisitudes de la hermana Lupe, el lector puede seguir los personajes del doctor Cerillo y de Juana Maura, joven de la cual Valentín se enamora.

La estructura narrativa de la obra no sigue un patrón fijo, ni temporal ni espacial pues se alternan de manera irregular las perspectivas diegéticas de los personajes principales en distintos momentos históricos e incluso biográficos. Los fragmentos tienen distinta longitud y solamente a veces los saltos temporales resultan evidentes; por ejemplo, las partes dedicadas a Juana Maura -diseminadas desde el principio a lo largo de toda la novela- se refieren al tiempo más reciente y cercano al fin de la historia narrada. A lo largo de la novela se percibe el pasar del tiempo y de los acontecimientos macrohistóricos que hacen de fondo lejano a la vida en Perdomo; juntando todos los fragmentos narrativos, se puede reconstruir la evolución de la población norestina. A menudo el desarrollo temporal de los hechos, así como su efectiva ordenación cronológica, se pueden inferir a través del análisis del contexto narrativo, mientras que las referencias directas al marco temporal resultan ser muy pocas. En particular, es desde la perspectiva de la hermana Lupe que la novela nos proporciona ocasionalmente unas fechas exactas, estrictamente relacionadas con eventos históricos; por ejemplo, el personaje enmarca su contexto inicial señalando que su entrada al convento se da "por esos años -1931 o 32, a poco de terminada la lucha cristera- [cuando] había muchas conciencias culpables que compraban perdones dando dineros a los conventos" (p. 18-19). Además de entrelazar los hechos ficticios con las consecuencias de los eventos macrohistóricos, la narración de Elizondo evidencia la resistencia al cambio impuesto por la modernidad y las necesarias transformaciones que la comunidad fronteriza debe encarar, por causa del inevitable progreso globalizador ${ }^{32}$.

La frontera es un eje central en el desarrollo de la trama y evidentemente permea toda la novela, ubicua como si fuera un fondo inmanente. La buena y mala suerte de Narcedalia dependen de sus relaciones directas e indirectas con la frontera misma; si bien su fortuna se desarrolla en el comercio, sea con la capital mexicana, sea con el otro lado, su destino está igualmente entrelazado con los negocios ilícitos que su marido emprende en la frontera. El encuentro con Valentín acontece significativamente en un puesto de comida en la frontera, donde el joven trabaja como aprendiz de mesero; infatuada, Narcedalia hace todo lo posible para que él se case con ella, básicamente prometiéndole una vida acomodada sin necesidad de trabajar ni preocuparse de cuestiones económicas. El doctor Cerillo

\footnotetext{
${ }^{32}$ GÚZMAN, Nora. Todos los caminos... Op. cit., p. 9.
} 
también conoce a su segunda mujer Hortensia Galindo "en la misma frontera donde Narcedalia se topó con su meserito" (p. 147), e igualmente -aunque por motivos distintos- la relación se revelará un fracaso. Hortensia es víctima de la actitud norteña hacia los extranjeros, encarnada por los pobladores de Perdomo que difícilmente aceptan "a un extraño, a un fuereño; cuando alguno llegaba le hacían caras agradables, eran corteses, pero hasta ahí; la propia deferencia servía de muro, de límite infranqueable" (p. 150). Asimismo, cuando la mujer intenta estrechar una relación amigable con la protagonista, Narcedalia declina pues "al igual que todo Perdomo, era muy renuente para ir a cenar a otra casa, o para aceptar comidas así porque sí" (p. 193); Hortensia se da cuenta, por lo tanto, de que a pesar de estar tan cerca de Estados Unidos y sus costumbres, Perdomo es un lugar distinto y "no se amansaba tan fácilmente" (p. 194). El carácter norteño, enraizado en las necesidades propias del territorio inhóspito y el recelo hacia el exterior, se hace frontera y límite a su vez.

La relación geoidentitaria peculiar de la región fronteriza queda representada por uno de los personajes fundamentales de la novela, el doctor Sergio Garza, conocido como Cerillo, al cual Elizondo dedica largos y detallados fragmentos de la novela. Se trata de un hombre que, después de formarse como médico en la capital del país, tiene la frontera como meta ideal, por lo que decide quedarse ejerciendo la profesión en Villa Perdomo (p. 10) por más de cuarenta años. Su afición por la región fronteriza deriva, al parecer, de su claustrofobia (p. 9) y de su deseo de "ser médico entre rural y urbano" (p. 10) atendiendo a los habitantes de Perdomo y todas las poblaciones de los alrededores "rumbo a la frontera" (p. 94). Sea su trabajo sea su atormentada vida sentimental lo llevan a relacionarse constantemente con el confín administrativo; metafóricamente, las vicisitudes a lo largo de la novela obligan también a Cerillo a rozar los límites de su ética profesional.

El personaje relacionado más estrechamente con el cruce fronterizo en sí y con el otro lado es Valentín, sobre todo a causa de su involucramiento en actividades ilícitas, o "negocio de frontera" (p. 23). La ingenuidad propia del personaje-que se deja arrastrar por su deseo de éxito y satisfacción personal- quizás representa lo que a menudo es el mecanismo más simple de la participación de civiles en el crimen organizado. Sin pensar en consecuencias negativas y calculando mal el alcance de sus acciones, Valentín acaba siendo un títere en el negocio transnacional del narcotráfico, perjudicando la vida de su familia de manera irreparable. Su hijo se acostumbra a cruzar el confín en su compañía y entretenerse de alguna manera solo, mientras que "su padre arreglaba algunos asuntos" (p. 386) que Elizondo nunca describe en detalle; sin embargo, queda claro el papel de Valentín en abrir el paso y apoyar las actividades de un grupo narcotraficante en Perdomo. La frontera es por definición un lugar donde se encuentran negocios ilícitos, al borde de la legalidad, y por ende individuos involucrados en este tipo de actividades. En momentos de necesidad, Narcedalia se sirve de hombres toscos, que se dedican a actividades turbias e ilegales, y con los cuales la mujer contacta en la frontera. Por ejemplo, cuando debe resolver una disputa con su vecino, Narcedalia contrata diez hombres "en la frontera, que tenían fama de pendencieros, además de que, de los diez, ocho eran ex presidiarios" (p. 81), que se disfrazan de peones y obedecen a sus órdenes, demostrando al vecino su propio poder de manera rotunda y 
amenazadora. Cada vez que aparecen comparsas amenazando la paz de Perdomo, se trata de desconocidos que "se vinieron directo desde la frontera" (p. 402) para emprender algún tipo de fechoría. Por el contrario, el ir y venir por la frontera desde Perdomo es revelador de una posición socioeconómica relativamente acomodada. Por un lado, Narcedalia hace "viajes semanales a la frontera, en parte por ver a la familia de su marido, pero sobre todo por los negocios" (p. 185); por otro, los habitantes de escasos recursos no tienen motivos ni posibilidades de cruzar, como la joven Juana Maura, que "nunca había ido a la frontera, es más, nunca había salido de Perdomo" (p. 400).

\section{El impacto social del progreso a través de la novela}

A lo largo de Narcedalia Piedrotas, las alusiones temporales son muy escasas y hay que reconstruir la ubicación temporal de los hechos a través de detalles contextuales, en particular relacionados precisamente con el desarrollo tecnológico y sociohistórico de la región fronteriza. A finales del siglo XIX, el pueblo ficticio imaginado por Elizondo se enfrenta por primera vez de manera impactante al progreso técnico y sus consecuencias.

El poblado de Villa Perdomo se encuentra fuera de las zonas de desarrollo urbano, como cualquiera de las pequeñas poblaciones diseminadas en el árido territorio norestino; sin embargo, por sus alrededores pasa la vía de ferrocarril que conduce al cruce fronterizo. Tal posición permite un acceso a los lugares de intercambio comercial y también a las conexiones con las redes del crimen organizado; cuando Narcedalia instala sus establos cerca de la vía del tren por comodidad, sin saberlo en ese entonces, crea también "un lugar propicio para que las púas de la perdición destilaran su letal untura" (p. 211). Descrita como una zona famosa por "el ganado mular" (p. 87), Perdomo se sustenta gracias a tal actividad hasta la llegada de medios de transportes modernos, como el tren y el automóvil. Según la narrativa de Elizondo, que retoma el recelo social hacia las innovaciones técnicas, en principio, la población local considera que el ferrocarril "destruyó la bonanza de tres siglos de mercadeo acémila. En muy pocos años ya nadie quiso las mulas y los perdomenses no las pudieron vender más" (p. 91). De la misma manera, la difusión de la producción de energía eléctrica representa una innovación, en principio, percibida como negativa, pues sustituye la energía animal proporcionada por las actividades ganaderas locales. La llegada de nuevas fuentes de energía, como el vapor, el carbón y el petróleo, comporta una verdadera revolución en el pueblo, "un cambio radical que desgració a Perdomo y lo hundió en la desesperación" (p. 91). Salir de tal hundimiento económico toma a la población largos años; a finales del siglo XIX, el estancamiento se resuelve con el desarrollo de actividades agrícolas y un sector ganadero distinto del antecedente, esta vez dedicado al bovino.

La modernización agrícola local es impulsada por la aportación técnica de Guango, el principal personaje de origen chino de la novela. Se trata de una presencia relevante desde el punto de vista microhistórico, pues describe la realidad cotidiana de la inmigración china en las zonas fronterizas de México. La caracterización del chino Guango -distorsión local de su nombre chino, Wüang 
Wüong Tse- resulta muy interesante, pues Elizondo dedica un apartado de quince páginas (pp. 96-111) a su historia personal; a través de pequeños detalles quizás aparentemente insignificantes, se asoman las conexiones de la novela con un conocimiento multifacético de la historia regional. Guango ya no viste la ropa occidental que "había usado cuando trabajó para los ferrocarriles, en las Californias, recién llegado de la Gran China" (p. 98); la mano de obra china fue fundamental, especialmente para compañías norteamericanas como la Ferrocarril Central Mexicano, que se ocupó, por ejemplo, de la construcción del ferrocarril que llegaba a la fronteriza Ciudad Juárez y de las conexiones con la red de ferrocarril en territorio estadounidense. Como se ha destacado en el primer apartado, la migración estacional de mano de obra mexicana fue regulada por programas y acuerdos binacionales a lo largo del siglo XX. Desde el trazado de la frontera entre México y Estados Unidos, los empleadores estadounidenses, apoyados por el gobierno, favorecían la inmigración desde el país vecino, mientras que la inmigración de trabajadores de origen distinto era a menudo limitada y dificultada por abiertas razones de índole racial ${ }^{33}$. El ostracismo -institucional y discursivo- se enfocaba especialmente en los chinos; debido a las restricciones raciales que regulaban el desembarque en los puertos estadounidenses, a menudo los migrantes chinos llegaban a las costas de México para luego intentar el cruce fronterizo ${ }^{34}$. En la región se fueron constituyendo comunidades chinas, ubicadas en ambos lados de la frontera y caracterizadas por su integración cultural y lingüística muy parcial. Se trata, además, de poblaciones que fueron objeto de intensa discriminación en ambos países, víctimas de articulados movimientos antichinos y represiones que en ocasiones desataron conflictos muy violentos ${ }^{35}$. En México la sinofobia ${ }^{36}$ alcanzó el nivel legislativo y si bien existen unos estudios muy interesantes sobre el tema ${ }^{37}$, la discriminación y represión de los migrantes chinos sigue siendo un tópico invisibilizado por la historiografía oficial mexicana ${ }^{38}$ y también en el discurso público nacional. Muy hábilmente, Elizondo destaca el papel innovador que tuvieron los chinos en México, en particular con respecto a la introducción de técnicas de cultivo eficientes. En Perdomo, la mayoría de los cambios impulsados por el camino hacia el progreso emprendido por el gobierno porfirista acontecieron "a fines del siglo XIX, por el mismo tiempo en que llegó el chino Guango con todas sus innovaciones alimenticias" (p. 91); el migrante chino fue, por ejemplo, "el primero en importar un molino de viento para sacar agua, y luego el primero en tener una planta eléctrica doméstica" (p. 108). Desde su llegada al pueblo, el personaje plantea una actividad agrícola, enfocada en el cultivo hortícola, especialmente productiva gracias a obras hidráulicas y técnicas de cultivo asiáticas. Consecuentemente a la prosperidad de tal

\footnotetext{
${ }^{33}$ DURAND, Jorge. Historia mínima... Op. cit.

${ }^{34}$ YANKELEVICH, Pablo. ¿Deseables o inconvenientes? Las fronteras de la extranjería en el México posrevolucionario. Ciudad de México: Bonilla Artigas Editores; Iberoamericana, 2011.

${ }_{35}$ MONTEÓN GONZÁLEZ, Humberto y TRUEBA LARA, José Luis. Chinos y antichinos en México. Documentos para su estudio. Ciudad de México: Unidad Editorial; Gobierno de Jalisco, 1988.

${ }^{36}$ GÓMEZ IZQUIERDO, José Jorge. La sinofobia de los mexicanos: una historia de prejuicios y estereotipos racistas. En: China-México: oportunidades y retos de la economía de la República Popular China para México. Universidad Nacional Autónoma de México, 2007.

${ }^{37}$ GÓMEZ IZQUIERDO, José Jorge. El movimiento antichino en México (1871-1934). Problemas del racismo y del nacionalismo durante la Revolución Mexicana. Ciudad de México: INAH, 1991.

${ }^{38}$ TREVIÑO RANGEL, Javier. Racismo y nación: comunidades imaginadas en México. Estudios Sociológicos. 2008, vol. 26, n. 78, pp. 669-694.
} 
actividad, el chino y sus descendientes alcanzarán un elevado nivel de bienestar, extendiendo sus propiedades y constituyendo un núcleo comunitario separado del resto del pueblo, con el cual mantienen casi exclusivamente relaciones laborales y comerciales. La tendencia de los migrantes chinos a la construcción de comunidades integradas de manera mínima es evidente también a través de la actitud de Guango hacia los idiomas fronterizos; a lo largo de su vida "pensó y habló fundamentalmente en chino" (p. 97), limitando fuertemente su aprendizaje y uso del inglés antes y del español después. Además de verduras y flores ornamentales, Guango cultiva y prepara la amapola, trayendo el opio a Perdomo; si bien las reconstrucciones sobre el origen del cultivo de amapola en México discrepan, se destaca la contribución de los migrantes chinos sea en las técnicas de cultivo y elaboración, sea en la difusión del consumo de opiáceos ${ }^{39}$.

Con respecto al impacto del progreso en la vida cotidiana y, en particular, doméstica, la familia Vega es el vehículo de representación ideal. La protagonista de la novela pertenece a una familia desafortunada, cuyas vicisitudes la obligan a sacarse sola adelante; sin embargo, Narcedalia es una mujer muy decidida, que toma la economía familiar en sus manos y -a lo largo de su vida-consigue alcanzar un nivel de bienestar notable. Elizondo narra que "Narcedalia y familia eran quienes se daban la mejor vida en todo Perdomo. Tenían camionetas; casa grandota" ( $p$. 278) con ventiladores en cada habitación y una alberca. Es más, poseen "radio, tocadiscos y otros lujos inusitados" (p. 278) como aparatos eléctricos que, paradójicamente, ni siquiera utilizan o ni pueden usar porque son adecuados al estilo de vida estadounidense y le faltan accesorios esenciales. La posesión de varias camionetas representa también un nivel económico destacado del resto de la población de Perdomo; a lo largo de la novela, la camioneta en sí se hace símbolo del desastre que destrozará la fortuna de Narcedalia. De manera exacta, Elizondo asimila la camioneta al quehacer del narcotráfico, poniendo la narración ficcional en relación con la realidad mexicana contemporánea; lo que era un medio de transporte empleado por su versatilidad en zonas rurales, la troca, se ha vuelto elemento estético identitario entre los integrantes del crimen organizado. Debido a su marco cronológico, en Narcedalia Piedrotas los elementos característicos del narco apenas se asoman y, sin embargo, están presentes de manera reconocible. Por lo tanto, Valentín tiene una "camioneta chula, de fuego pintado a los lados" (p. 49), "lujosa" (p. 127), con la cual va a buscar a su amante, Juana Maura; la relación que el hombre entrelaza con la joven lo lleva precisamente a inmiscuirse con el narcotráfico y simboliza el principio del fin de la honestidad de la familia Vega.

Gracias a su posición de empresaria acomodada, entre los principales lujos que Narcedalia comparte generosamente con sus vecinos se encuentra la radio. Aunque la historia de la difusión de la radio en territorio mexicano empieza en los años 20 , es entre los años 40 y 60 cuando el medio alcanza popularidad y una difusión más amplia fuera de los grandes centros urbanos ${ }^{40}$. El acceso a las frecuencias de onda corta permite a Narcedalia sintonizar "una estación de la capital" (p. 138); en

\footnotetext{
39 TRUJILLO BRETÓN, Jorge Alberto. La casa del silencio: chinos y mexicanos en el mercado ilegal del opio y sus derivados en Guadalajara, Jalisco, 1917-1950. Passagens. 2017, vol. 9, n. 3, p. 365.

${ }^{40}$ FERNÁNDEZ CHRISTLIEB, Fátima. Los medios de difusión masiva en México. Ciudad de México: Juan Pablos, 1988.
} 
Perdomo, ella es "la primera en tener un aparato de radio en casa" (p. 232), que saca a la calle al anochecer para deleitarse y dejar que los vecinos gocen también de la música, sintonizándolo en radiodifusoras de la capital. Su disposición para compartir el medio posibilita a los pobladores de Perdomo estar al tanto de las modas musicales nacionales, reflejando la realidad de un país al comienzo de su desarrollo mediático. Además, la novela registra la subsecuente difusión de radionovelas que llevan a la comunidad a "reunirse fuera de la casa de Narcedalia, cada día a la misma hora, para escuchar el cuento" (p. 240). Durante la que se considera como la edad de oro de la radionovela mexicana (1940-1960), se desarrolló una programación variada y muy popular que tocaba géneros narrativos distintos y formaba parte de la representación nacional mexicana a través de los medios de masas ${ }^{41}$. Narcedalia también lleva a Perdomo el cine. Un día estando en la frontera, ella decide llevar a su hijo Víctor al cine; una vez dentro "se le ocurrió que una cosa así, en Perdomo, le dejaría muy buena lana" (p. 252). Aprovechando la carretera recién asfaltada, Narcedalia consigue montar rápidamente un cine-terraza haciendo llegar todos los aparatos necesarios del otro lado. Efectivamente, el negocio se revela muy rentable, al punto que sin "esforzarse mucho. El cine-terraza le dejaba más dinero, en proporción, que cualquiera de sus otros negocios" (p. 272). Narcedalia además establece la programación de su cine, aunque por su propia afición por las películas cómicas, "el cine terraza pasaba puras repetidas" (p. 276).

El papel de la frontera misma en el alcance del progreso es evidente; Elizondo disemina la novela con detalles que informan al lector sobre la innovación e intercambio técnico que conlleva la posición fronteriza. Uno de los momentos en que los negocios de Narcedalia toman un giro provechoso es cuando ella decide montar una marranera para vender su carne "en la frontera" (p. 93), en vez de limitar su comercio a los alrededores de Perdomo. De la frontera llegan, por ejemplo, tejidos de buena calidad y ropa más a la moda; en el caso de Hortensia Galindo, cuyo buen gusto en el vestir es reconocido por los perdomenses, sus vestidos "habían sido de sus hermanas que vivían con la frontera. Eran vestidos bien chulos" (p. 150). Los socios turbios de Valentín viven "del otro lado de la frontera" (p. 318), donde él se traslada cuando debe rendir cuentas. A lo largo de su carrera, la fama del doctor Cerillo lo convierte en el "mejor médico de toda la región, incluido este y el otro lado del río" (p. 86); al mismo tiempo, cuando hay necesidad de consultas a especialistas, los que pueden permitírselo económicamente buscan servicios en una "clínica del país vecino" (p. 222), donde la asistencia médica es más avanzada.

La línea narrativa protagonizada por la hermana de Narcedalia, Guadalupe, se deslinda de la suerte de Villa Perdomo y se enfoca en el convento donde la mujer asume encargos de responsabilidad cada vez mayores. Sin embargo, el tema del progreso, de la resistencia popular y las necesarias transformaciones sociohistóricas que eso implica resulta central. Es precisamente Lupe quien -igual que su hermana, aunque en distinto contexto- lucha para traer innovaciones técnicas al convento, mejorando la vida de las monjas y estableciendo negocios rentables. El paralelo entre las dos hermanas Vega es evidente e interesante, pues muestra dos caras distintas de la difusión del progreso en el norte mexicano. Aun sin cultivar su relación familiar, las dos encarnan un espíritu innovador afín atento a aprovechar las

\footnotetext{
${ }^{41}$ VALADEZ CALDERÓN, Irma. La radionovela mexicana, en agonía. Etcétera. Oct. 2009, p. 42.
} 
transformaciones técnicas y sociales, y sobre todo la posición de favorable cercanía con la frontera.

\section{Conclusiones}

La novela Narcedalia Piedrotas nos ofrece un retrato exacto de la realidad cotidiana de los norestenses y, al mismo tiempo, una reconstrucción -desde una perspectiva microhistórica- de las dinámicas sociales relacionadas con la llegada de elementos modernos en la región fronteriza mexicana. Ricardo Elizondo Elizondo consigue representar los valores socioculturales, las creencias y las actitudes que pudo observar en primera persona a lo largo de su carrera como historiador, enfocada en la historia privada y local de su estado. El elemento narrativo literario resulta fundamental en la reconstrucción eficaz de la microhistoria, en su proceso de interpretación y escritura, así como en la posibilidad de permitir al público disfrutar y acercarse a la historia. Su trabajo narrativo e historiográfico pone el énfasis en la observación directa y en la comprensión de las evoluciones macrohistóricas a través de sus repercusiones a nivel local, cotidiano y doméstico. Apostando por una lectura de la realidad cercana a la vida privada regional ${ }^{42}$, Elizondo basa su narrativa en sus estudios histórico y consigue añadir un importante fragmento a la reconstrucción de la historia norteña y norestina en particular.

\section{Bibliografía}

CARR, Barry. Las peculiaridades del norte mexicano, 1880-1917. Historia Mexicana. 1973, vol. 22, n. 3, pp. 320-346.

CEBALLOS RAMÍREZ, Manuel. La conformación del noreste histórico mexicano: larga duración, identidad y geopolítica. Secuencia. 2006, n. 65, pp. 7-37.

CERUTTI, Mario. Frontera y desarrollo empresarial en el norte de México (18501910). Frontera Norte. 2001, vol. 13, n. 2, pp. 283-301.

CERUTTI, Mario. La historia económica y empresarial del norte de México: un cuarto de siglo de investigación. Monterrey: Universidad Autónoma de Nuevo León; AHENME, 2017.

DE VITO, Christian G. Verso una microstoria translocale (micro-spatial history). Quaderni storici. 2015, n. 3, pp. 815-833.

DEAR, Michael y LECLERC, Gustavo (eds.). Postborder city. Cultural spaces of Bajalta California. Nueva York: Routledge Publishing, 2003.

DURAND, Jorge. Historia mínima de la migración México-Estados Unidos. Ciudad de México: El Colegio de México, 2016.

ELIZONDO ELIZONDO, Ricardo. Relatos de mar, desierto y muerte. Xalapa:

\footnotetext{
${ }^{42}$ LEVI, Giovanni. II piccolo, il grande e il piccolo. Intervista a Giovanni Levi. Meridiana. 1990, n. 10, p. 224 y ss.
} 
Universidad Veracruzana; Leega, 1981.

ELIZONDO ELIZONDO, Ricardo. Setenta veces siete. Ciudad de México: Leega, 1987.

ELIZONDO ELIZONDO, Ricardo. Narcedalia Piedrotas. $2^{\underline{a}}$ ed. Ciudad de México: Fondo de Cultura Económica, 2002.

ELIZONDO ELIZONDO, Ricardo. Lexicón del Noreste de México. Ciudad de México: Fondo de Cultura Económica; Instituto Tecnológico y de Estudios Superiores de Monterrey, 1996.

ELIZONDO ELIZONDO, Ricardo. Un lexicón del noreste. En: ORTEGA RIDAURA, Isabel. El noreste: reflexiones. Monterrey: Fondo Editorial de Nuevo León, 2006, pp. 193-202.

FERNÁNDEZ CHRISTLIEB, Fátima. Los medios de difusión masiva en México. Ciudad de México: Juan Pablos, 1988.

GARCÍA CANCLINI, Néstor. Culturas híbridas. Estrategias para entrar y salir de la modernidad. Ciudad de México: Grijalbo, 1990.

GÓMEZ IZQUIERDO, José Jorge. El movimiento antichino en México (1871-1934). Problemas del racismo y del nacionalismo durante la Revolución Mexicana. Ciudad de México: INAH, 1991.

GÓMEZ IZQUIERDO, José Jorge. La sinofobia de los mexicanos: una historia de prejuicios y estereotipos racistas. En: China-México: oportunidades y retos de la economía de la República Popular China para México. Universidad Nacional Autónoma de México, 2007.

GREEN, Stanley. C. La república del Río Grande y Nuevo León. En: ORTEGA RIDAURA, Isabel. El noreste: reflexiones. Monterrey: Fondo Editorial de Nuevo León, 2006, pp. 53-60.

GRIMSON, Alejandro. Las culturas son más híbridas que las identificaciones: diálogos inter-antropológicos. Anuário Antropológico. 2008, vol. 33, n. 1, pp. 223267.

GÚZMAN, Nora. Todos los caminos conducen al norte: la narrativa de Ricardo Elizondo Elizondo y Eduardo Antonio Parra. Monterrey: Fondo Editorial de Nuevo León, 2009.

LEVI, Giovanni. Il piccolo, il grande e il piccolo. Intervista a Giovanni Levi. Meridiana. 1990, n. 10, pp. 211-234.

MARINI, Anna Marta. Narcedalia Piedrotas y la construcción microhistórica de la identidad fronteriza norteña. n América sin Nombre. 2018, n. 23, pp. 203-209. 
MÁRQUEZ MARTÍNEZ, Teresa. Los archivos de ferrocarriles nacionales de México. América latina en la historia económica. 2005, n. 23, pp. 119-130.

MONTEÓN GONZÁLEZ, Humberto y TRUEBA LARA, José Luis. Chinos y antichinos en México. Documentos para su estudio. Ciudad de México: Unidad Editorial; Gobierno de Jalisco, 1988.

ORTEGA RIDAURA, Isabel. Introducción. En: ORTEGA RIDAURA, Isabel. El noreste: reflexiones. Monterrey: Fondo Editorial de Nuevo León, 2006, pp. 11-16.

PARDO FERNÁNDEZ, Rodrigo. La ficción narrativa de la frontera: el río Bravo en tres novelas mexicanas. Frontera Norte. 2013, vol. 25, n. 49, pp. 157-178.

RODRÍGUEZ LOZANO, Miguel G. Notas en torno al mundo narrativo de Ricardo Elizondo Elizondo. Proyecto Hacia una microhistoria literaria: Gerardo Cornejo, Jesus Gardea, Ricardo Elizondo y Daniel Sada. Ciudad de México: Universidad Nacional Autónoma de México, 1998.

SÁNCHEZ ANDRÉS, Agustín. México en el siglo XX: del Porfiriato a la globalización. Madrid: Arco Libros, 2010.

SANTAMARÍA, Francisco J. Diccionario de mejicanismos. Ciudad de México: Editorial Porrúa, 1959.

TORRES, Vicente Francisco. Esta narrativa mexicana. Ed. revisada. Ciudad de México: Universidad Autónoma Metropolitana, 2007.

TORRES, Vicente Francisco. Un maestro del desierto y del estilo. Tema y variaciones de literatura. 2012, semestre I, n. 38, pp. 141-159.

TREVIÑO RANGEL, Javier. Racismo y nación: comunidades imaginadas en México. Estudios Sociológicos. 2008, vol. 26, n. 78, pp. 669-694.

TRUJILLO BRETÓN, Jorge Alberto. La casa del silencio: chinos y mexicanos en el mercado ilegal del opio y sus derivados en Guadalajara, Jalisco, 1917-1950. Passagens. 2017, vol. 9, n. 3, pp. 361-390.

VALADEZ CALDERÓN, Irma. La radionovela mexicana, en agonía. Etcétera. Oct. 2009, pp. 42-44.

VÁZQUEZ, Josefina Zoraida. La supuesta República del Río Grande. Historia Mexicana. 1986, vol. 36, n. 1, pp. 49-80.

YANKELEVICH, Pablo. ¿Deseables o inconvenientes? Las fronteras de la extranjería en el México posrevolucionario. Ciudad de México: Bonilla Artigas Editores; Iberoamericana, 2011.

YÁÑEZ REYES, Sergio. El Instituto Nacional de Antropología e Historia: 
Anna Marta MARINI. Modernidad y progreso a través de la reconstrucción microhistórica literaria del noreste mexicano en Narcedalia piedrotas.

antecedentes, trayectoria y cambios a partir de la creación del CONACULTA. Cuicuilco. 2006, vol. 13, n. 38, pp. 47-72. 